\title{
Extensive Pneumatosis Intestinalis in Association With Celiac Disease: A Case Report
}

\author{
Sanjeev Dayal ${ }^{\mathrm{a}, \mathrm{b}}$, Robert Bolton-Jones ${ }^{\mathrm{a}}$, Sheila Stallard ${ }^{\mathrm{a}}$, Lazlo Romics Jr ${ }^{\mathrm{a}}$
}

\begin{abstract}
Pneumatosis intestinalis (PI) is generally regarded as a worrying sign due to its relatively frequent association with serious conditions such as acute gastrointestinal necrosis. While PI can also be associated with a wide spectrum of benign conditions, its diagnosis as benign is usually accepted with the exclusion of gangrenous bowel, even in the absence of other clinical signs suggesting ischemia. We report a case of extensive PI in a patient with celiac disease and discuss its management and the role of diagnostic laparoscopy in this condition with emphasis on the different etiologies of PI.
\end{abstract}

Keywords: Pneumatosis intestinalis; Celiac disease; Laparoscopy; Management

\section{Introduction}

Pneumatosis intestinalis (PI) is defined as gas in the bowel wall. PI can signify a wide spectrum of diseases that range from conditions with serious implications like bowel infarction and necrosis to other benign conditions like celiac disease (CD) [1]. PI has been classified into a benign primary form occurring in $15 \%$ of cases and a secondary form occurring in the remaining $85 \%$ of cases associated with obstructive and necrotic gastrointestinal disease and pulmonary disease $[1,2]$.

Differential diagnosis of PI is rather challenging if it is

Manuscript accepted for publication October 5, 2010

${ }^{a}$ Department of Surgery and Department of Gastroenterology, Victoria Infirmary, Greater Glasgow and Clyde NHS Trust, G42 9TY, United Kingdom

${ }^{\mathrm{b}}$ Corresponding author: Sanjeev Dayal,

Email: sanjeevdayal@doctors.net.uk

doi:10.4021/jmc63w not associated with obvious bowel ischemia. Conversely, detection of PI on radiological imaging can misleadingly direct the patient's work-up towards necrotic bowel, even if it is clinically not suggested. Since PI is generally regarded as a worrying sign, etiology of it is urgently sought in most cases. Furthermore, due to the widespread use of cross-sectional imaging in the acute setting these days, the diagnosis of benign PI has significantly increased making it very important for clinicians to be aware of this condition.

The association of PI with celiac disease is a very rare condition and to date only ten cases have been reported in the literature with only one in the UK [2]. We present a case of PI associated with refractory celiac disease, and discuss the role of sequential radiological imaging and diagnostic laparoscopy during its management.

\section{Case Report}

A 60-year-old man with no significant past medical history had been progressively unwell for eight weeks with complaints of abdominal bloating, diarrhea, decreased appetite and weight loss prior to his admission. Previously, he has been diagnosed with celiac disease confirmed on duodenal biopsies four months earlier, and subsequently started on gluten free diet but continued to lose weight. An abdominopelvic CT scan performed prior to his admission was unremarkable. On examination he was a thin built man with vague abdominal tenderness on palpation. His laboratory tests revealed normal white cell count and CRP level, although serum albumin level was quite low $(17 \mathrm{~g} / \mathrm{L})$. Interestingly, routine abdominal X-ray and subsequent $\mathrm{CT}$ scan demonstrated extensive PI (Fig. 1,2). While on clinical and biochemical grounds (normal blood gas analysis) ischemic bowel was an unlikely diagnosis, we proceeded with the least invasive option of a diagnostic laparoscopy to exclude the above with absolute certainty given the impressive radiological findings. Laparoscopy showed viable bowel with subserosal bubbles of air along the mesenteric border of the small bowel (Fig. 3). The small bowel wall in itself looked as though it had subserosal blebs clustered together (Fig. 4). A diagnosis of benign secondary PI was made. The pa- 


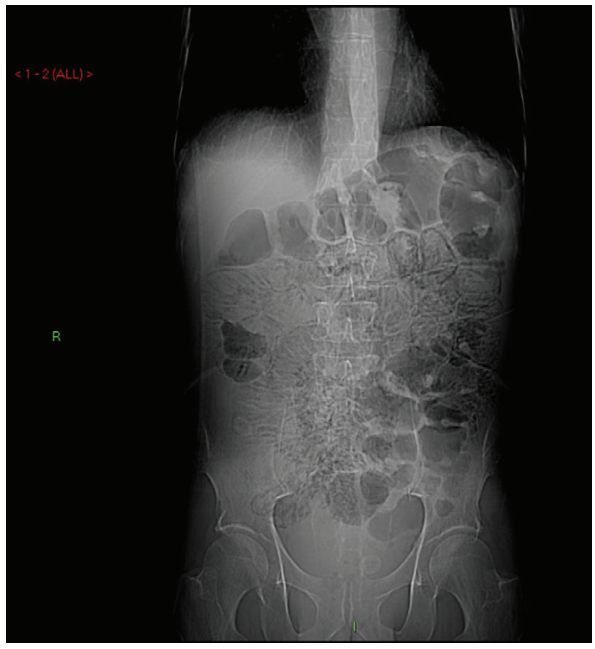

Figure 1. Abdominal X-ray demonstrating extensive pneumatosis intestinalis $(\mathrm{PI})$.

tient's further management included oxygen therapy, metronidazole and total parenteral nutrition, which significantly improved his diarrhea initially. On the tenth postoperative day, a barium follow through ruled out ulcerative jejunitis and EATL (Enteropathy Associated T-cell Lymphoma) and showed full resolution of the previous extensive PI. This was also confirmed by an abdomino-pelvic CT scan.

Unfortunately, the patient did not tolerate semi-elemental enteral feeding due to worsening diarrhea and this significantly limited treatment options. Clostidrium difficile infection and other infective pathology were ruled out by stool cultures and CMV, HIV and autoimmune etiology were ruled out by negative serology. Furthermore, inflammatory bowel disease and microscopic colitis were excluded by colonoscopic biopsies. The nutritional status of the patient continued to deteriorate despite parenteral nutrition and his

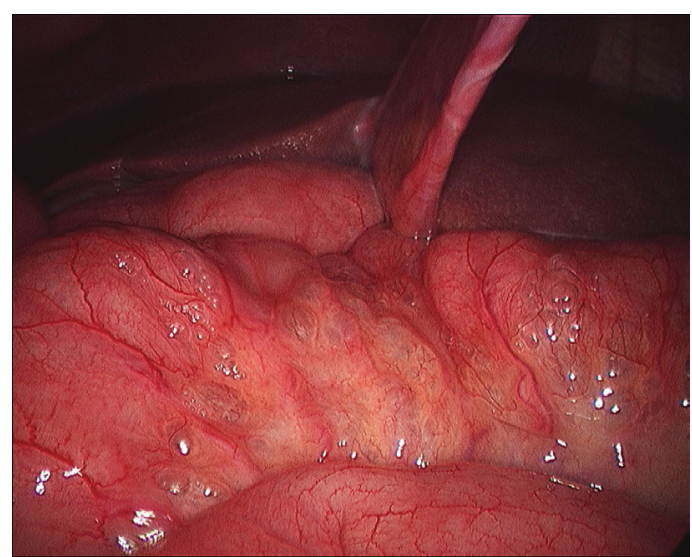

Figure 3. Laparoscopy showing viable bowel with subserosal bubbles of air along the mesenteric border of the small bowel.

serum albumin dropped to $11 \mathrm{~g} / \mathrm{L}$. Immuno-histochemical staining of intraepithelial lymphocytes (IEL) in his duodenal biopsies did not confirm the clinical suspicion of refractory celiac disease. Regrettably, the patient's general condition and diarrhea continued to worsen and he passed away five weeks after his admission.

\section{Discussion}

Secondary PI in adults can be caused by a wide range of diseases. These range from COPD, immuno-compromised states, collagen vascular disease, celiac disease, bowel trauma, bowel obstruction, infections secondary to CMV, Clostidrium difficile and HIV, to immediate life threatening conditions like bowel infarction and necrosis [3]. PI can affect any part of the GI tract, although most frequently involves the small bowel (42\%) and the colon (36\%) [4]. While sub-

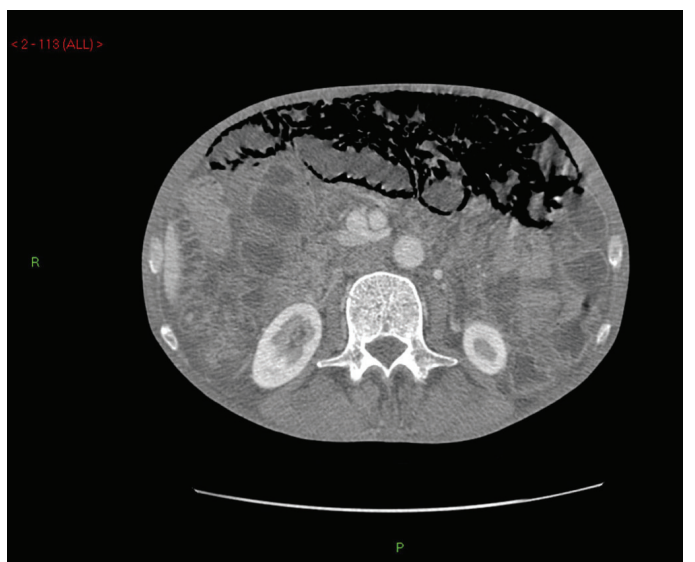

Figure 2. Abdominal CT scan demonstrating extensive pneumatosis intestinalis $(\mathrm{PI})$.

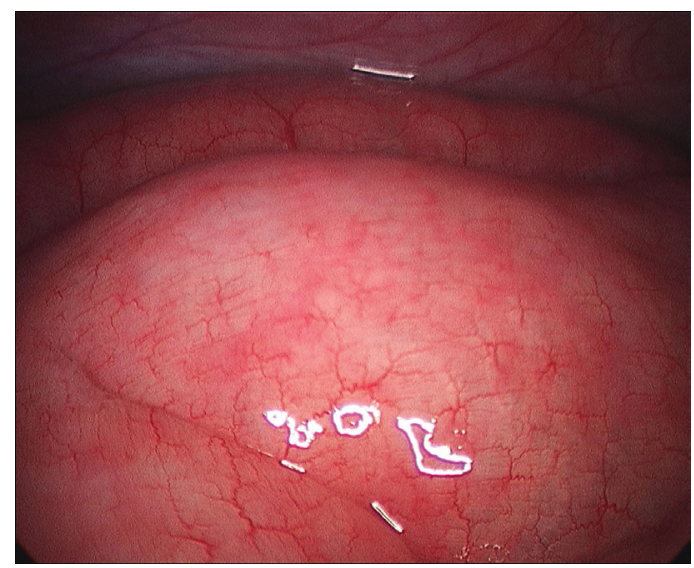

Figure 4. Laparoscopy showing the small bowel wall. 
serosal cysts are more common in the small bowel, submucosal cysts are more frequent findings in the colon.

Different etiologies have been proposed to explain the pathogenesis of PI. The mechanical theory suggests that gas dissects into the bowel wall secondary to disruption in the mucosal integrity due to various factors such as ischemia, trauma or infection [5]. It has also been suggested that gas can tract through the tissues and along the root of the mesentery in patients with COPD [5]. The biochemical theory, on the other hand, proposes that luminal bacteria produce significant amounts of hydrogen as a result of fermentation of mostly carbohydrates, which is then forced into the bowel wall as intraluminal pressure rises. Hydrogen content of the cysts has been reported to be as high as 50\% [6]. The bacterial theory proposes that gas-forming bacteria enter the bowel wall through breaches in the mucosa. Resolution of PI has been seen with antibiotics leading some to believe that bacteria may have a role to play in this [7].

Symptoms and signs of PI can be related to its presence or the underlying disorder giving rise to it. They also depend on which part of the bowel is affected. Small bowel pneumatosis has been reported to cause vomiting, abdominal distension, weight loss, abdominal pain and diarrhea. Large bowel pneumotosis on the other hand has been reported to cause diarrhea, hematochezia, abdominal pain and distension, constipation and tenesmus [4].

Diagnosis of PI can be made using different radiological imaging. An abdominal radiograph can identify PI in $66 \%$ of cases [8]. It is seen as different patterns of radiolucencies in the form of linear, curvilinear, small bubbles or collection of cysts within the bowel wall. Cystic collections of gas are more suggestive of primary PI. PI associated with portal venous gas is an ominous sign for bowel ischemia. A CT Scan is more sensitive in detecting PI and may also suggest underlying cause as compared to an abdominal x-ray [9]. However, given that its sensitivity to diagnose ischemic bowel is only in the range of $82 \%$ [10], it can make reporting PI secondary to ischemic bowel challenging for the radiologist in the absence of portal venous gas. To operate or not to operate can be the main dilemma in the management of PI. Intraabdominal catastrophe is clinically obvious in most cases however sometimes this may not be so on initial presentation. One can argue the need for a diagnostic laparoscopy in this patient given that he had no signs of peritonism, normal inflammatory markers and a normal arterial blood gas. The role of diagnostic laparoscopy however has been found to be reliable and accurate in the setting of PI associated with celiac disease $[8,11]$.

Once an acute intra abdominal emergency has been excluded the management of PI is largely conservative [12]. Oxygen therapy, antibiotics and elemental diet have been found to be mainstays of treatment, as we did in our patient. The rationale for the use of oxygen has been postulated to be two-fold. Firstly, oxygen is toxic to the anaerobic bacteria thought to be responsible for the gas production and secondly, increased partial pressures of oxygen in the venous blood and decreased partial pressure of nonoxygen gases create a diffusion gradient allowing the absorption of the latter [13]. Optimal amount and duration of oxygen therapy is however not known [14]. The rationale for using antibiotics is again targeted at the anaerobic bacteria. The successful application of metronidazole in treating PI has been described before [15]. Similarly, elemental diet has been reported to alter the colonic microflora, thereby helping in the resolution of PI [16].

Complications are seen in approximately $3 \%$ of cases with PI [17]. These include small and large bowel obstruction, volvulus, intussusception, pneumoperitoneum and hemorrhage, and these may warrant surgery.

Intraepithelial lymphocytes (IEL) in uncomplicated celiac disease have been shown to express $\mathrm{CD} 3+$ and $\mathrm{CD} 8+$ receptors which can be identified with immunohistochemical staining. In refractory $\mathrm{CD}$, the IELs have been found to be abnormal expressing only intracytoplasmic CD3 but not surface CD8 [18]. This aberrant clonal intraepithelial T cell population is however found only in $75 \%$ of cases of refractory celiac disease [19]. In our patient, infectious causes, malabsorption, ulcerative jejunitis, EATL, autoimmune enteropathy, inflammatory bowel disease and microscopic colitis were all ruled out. Since post mortem examination was not carried out due to lack of family's consent, we can only assume given the clinical course, that there was a significant association between celiac disease and pneumatosis intestinalis and the patient's death.

\section{Conclusion}

PI secondary to celiac disease is a rare but well-established condition. It can confront clinicians with the dilemma to operate or not to operate when faced with impressive radiological findings and the serious implications of PI and ischemic bowel. We believe that although diagnostic laparoscopy can be used to confirm PI to be benign, it is not always necessary to perform given that our understanding of this condition has greatly improved. Treating the underlying cause is the mainstay of treatment to achieve full resolution of PI.

\section{Conflict of Interest}

None

\section{References}

1. Bottiger C, Koch W, Lahn C, Mehilli J, von Beckerath N, Schomig A, Kastrati A. 4G/5G polymorphism of the plasminogen activator inhibitor-1 gene and risk 
of restenosis after coronary artery stenting. Am Heart J 2003;146(5):855-861.

2. Takahashi H, Ieiri I, Wilkinson GR, Mayo G, Kashima T, Kimura S, Otsubo K, et al. 5'-Flanking region polymorphisms of CYP2C9 and their relationship to S-warfarin metabolism in white and Japanese patients. Blood 2004;103(8):3055-3057.

3. Rizzo MT, Weber G. 1-Phosphatidylinositol 4-kinase: an enzyme linked with proliferation and malignancy. Cancer Res 1994;54(10):2611-2614.

4. Molloy RG, Moran KT, Waldron RP, Brady MP, Kirwan WO. Massive incisional hernia: abdominal wall replacement with Marlex mesh. Br J Surg 1991;78(2):242-244.

5. DiBello JN, Jr., Moore JH, Jr. Sliding myofascial flap of the rectus abdominus muscles for the closure of recurrent ventral hernias. Plast Reconstr Surg 1996;98(3):464469.

6. Mathes SJ, Steinwald PM, Foster RD, Hoffman WY, Anthony JP. Complex abdominal wall reconstruction: a comparison of flap and mesh closure. Ann Surg 2000;232(4):586-596.

7. Wurzner R, Joysey VC, Lachmann PJ. Complement component C7. Assessment of in vivo synthesis after liver transplantation reveals that hepatocytes do not synthesize the majority of human C7. J Immunol 1994;152(9):4624-4629.

8. Sandgren EP, Palmiter RD, Heckel JL, Daugherty CC, Brinster RL, Degen JL. Complete hepatic regeneration after somatic deletion of an albumin-plasminogen activator transgene. Cell 1991;66(2):245-256.

9. Caldironi MW, Romano M, Bozza F, Pluchinotta AM, Pelizzo MR, Toniato A, Ranzato R. Progressive pneumoperitoneum in the management of giant incisional hernias: a study of 41 patients. Br J Surg 1990;77(3):306307.

10. Taoudi S, Morrison AM, Inoue H, Gribi R, Ure J, Medvinsky A. Progressive divergence of definitive haematopoietic stem cells from the endothelial compartment does not depend on contact with the foetal liver. Development 2005;132(18):4179-4191.

11. Mayagoitia JC, Suarez D, Arenas JC, Diaz de Leon V. Preoperative progressive pneumoperitoneum in patients with abdominal-wall hernias. Hernia 2006;10(3):213217.

12. King JN, Didlake RH, Gray RE. Giant inguinal hernia. South Med J 1986;79(2):252-253.

13. Morris-Stiff GJ, Hughes LE. The outcomes of nonabsorbable mesh placed within the abdominal cavity: literature review and clinical experience. J Am Coll Surg 1998;186(3):352-367.

14. White TJ, Santos MC, Thompson JS. Factors affecting wound complications in repair of ventral hernias. Am Surg 1998;64(3):276-280.

15. Gaines BA, Colson YL, Kaufman CL, Ildstad S. Fa- cilitating cells enable engraftment of purified fetal liver stem cells in allogeneic recipients. Exp Hematol 1996;24(8):902-913.

16. Ko JH, Salvay DM, Paul BC, Wang EC, Dumanian GA. Soft polypropylene mesh, but not cadaveric dermis, significantly improves outcomes in midline hernia repairs using the components separation technique. Plast Reconstr Surg 2009;124(3):836-847.

17. Tran NV, Petty PM, Bite U, Clay RP, Johnson CH, Arnold PG. Tissue expansion-assisted closure of massive ventral hernias. J Am Coll Surg 2003;196(3):484-488.

18. Lipman J, Medalie D, Rosen MJ. Staged repair of massive incisional hernias with loss of abdominal domain: a novel approach. Am J Surg 2008;195(1):84-88.

19. Chua KN, Lim WS, Zhang P, Lu H, Wen J, Ramakrishna $\mathrm{S}$, Leong KW, et al. Stable immobilization of rat hepatocyte spheroids on galactosylated nanofiber scaffold. Biomaterials 2005;26(15):2537-2547.

20. Luijendijk RW, Hop WC, van den Tol MP, de Lange DC, Braaksma MM, JN IJ, Boelhouwer RU, et al. A comparison of suture repair with mesh repair for incisional hernia. N Engl J Med 2000;343(6):392-398.

21. Baptista ML, Bonsack ME, Delaney JP. Seprafilm reduces adhesions to polypropylene mesh. Surgery 2000;128(1):86-92.

22. Chang TM. Semipermeable Microcapsules. Science 1964;146(524-525.

23. Jenkins SD, Klamer TW, Parteka JJ, Condon RE. A comparison of prosthetic materials used to repair abdominal wall defects. Surgery 1983;94(2):392-398.

24. Amid PK, Shulman AG, Lichtenstein IL, Sostrin S, Young J, Hakakha M. Experimental evaluation of a new composite mesh with the selective property of incorporation to the abdominal wall without adhering to the intestines. J Biomed Mater Res 1994;28(3):373-375.

25. Panis Y, Nordlinger B, Delelo R, Herve JP, Infante J, Kuhnle M, Ballet F. Experimental colorectal liver metastases. Influence of sex, immunological status and liver regeneration. J Hepatol 1990;11(1):53-57.

26. de Vries Reilingh TS, van Geldere D, Langenhorst B, de Jong D, van der Wilt GJ, van Goor H, Bleichrodt RP. Repair of large midline incisional hernias with polypropylene mesh: comparison of three operative techniques. Hernia 2004;8(1):56-59.

27. Szabo A, Haj M, Waxsman I, Eitan A. Evaluation of seprafilm and amniotic membrane as adhesion prophylaxis in mesh repair of abdominal wall hernia in rats. Eur Surg Res 2000;32(2):125-128.

28. van 't Riet M, de Vos van Steenwijk PJ, Bonthuis F, Marquet RL, Steyerberg EW, Jeekel J, Bonjer HJ. Prevention of adhesion to prosthetic mesh: comparison of different barriers using an incisional hernia model. Ann Surg 2003;237(1):123-128.

29. Felemovicius I, Bonsack ME, Hagerman G, Delaney JP. 
Prevention of adhesions to polypropylene mesh. J Am Coll Surg 2004;198(4):543-548.

30. van't Riet M, Burger JW, Bonthuis F, Jeekel J, Bonjer HJ. Prevention of adhesion formation to polypropylene mesh by collagen coating: a randomized controlled study in a rat model of ventral hernia repair. Surg Endosc 2004;18(4):681-685.

31. Shawki S, Wexner SD. How safe is bowel preparation with oral sodium phosphate solution? Nat Clin Pract Gastroenterol Hepatol 2008;5(9):482-483. 